\title{
Randomised trial of routine versus selective paralysis during ventilation for neonatal respiratory distress syndrome
}

\author{
N J Shaw, R W I Cooke, A B Gill, N J Shaw, M Saeed
}

\begin{abstract}
The strategy of non-selective nueromuscular paralysis was compared with that of synchronised (fast rate) ventilation and selective paralysis in infants receiving mechanical ventilation for respiratory distress syndrome with chronic lung disease as the primary outcome measure. One hundred and ninety three infants weighing under $2000 \mathrm{~g}$ were randomly allocated to receive either pancuronium during mechanical ventilation in the acute phase of respiratory distress syndrome (non-selective group) or synchronised ventilation (initial ventilatory rate at or above that of the infant's) (selective group). Infants in the selective group received pancuronium if they were consistently expiring during the inspiratory phase of the ventilator cycle.

There was no significant difference between the groups with respect to birth weight, gestation, and sex distribution. There was no significant difference between the group with respect to death (selective 19\%, non-selective $16 \%$ ), pneumothorax (selective 14\%, non-selective $14 \%$ ), chronic lung disease (selective $49 \%$ ), non-selective $47 \%$ ), and oxygen dependency at 36 weeks' postmenstrual age (selective $32 \%$, non-selective $39 \%$ ).

Routine paralysis of ventilated infants has potential complications that may be avoided by using synchronised ventilation. As the latter is not associated with an increased incidence of long term respiratory complications, it is concluded that it is the optimum strategy of the two for ventilating infants with respiratory distress syndrome.

(Arch Dis Child 1993; 69: 479-482)
\end{abstract}

Liverpool Maternity

Hospital, Oxford

Street, Liverpool,

Merseyside L7 7BN

N J Shaw

$\mathrm{R}$ W I Cooke

A B Gill

N J Shaw

$M$ Saeed

Correspondence to:

Dr Ben N J Shaw.

Accepted 27 July 1993

When pressure limited time cycled mechanical ventilators were initially used for the treatment of respiratory distress syndrome in preterm neonates many infants died of fulminating bronchopulmonary dysplasia. Reducing the peak inspiratory pressures used and increasing the inspiratory time of the ventilatory cycle resulted in a reduction of the incidence of this
However pneumothorax, which may be a factor in the pathogenesis of intraventricular haemorrhage, still often occurred. ${ }^{1}$ It has been suggested that the use of neuromuscular blockers (for example pancuronium) may reduce its incidence either by preventing the infant expiring during the inspiratory phase of the ventilation cycle $^{2} 3$ or by preventing the generation of large transpulmonary pressures by the infants' inspiratory effort synchronising with the ventilator. ${ }^{4}$ Other workers have suggested that using a faster rate of ventilation (above 60 breaths per minute (bpm)) may 'synchronise' the infant's breathing with the ventilator and also reduce the incidence of pneumothorax. ${ }^{56}$ Infants receiving this form of ventilation occasionally require paralysis if they continue to expire asynchronously against the ventilator's inspiratory phase. ${ }^{7}$

There has been some concern that using a fast ventilator rate may cause an inadvertent rise in positive and expiratory pressure (PEEP) leading to circulatory impairment and also air trapping which may predispose to a higher incidence of pneumothorax than when neuromuscular paralysis is used. ${ }^{1}$ However, when the infant is paralysed he is wholly dependent on the ventilator and fluid balance may be more difficult to control.

There has been no direct comparison between these two ventilatory strategies with respect to acute or longer term respiratory problems. Furthermore, since the advent of the use of surfactant as treatment for respiratory distress syndrome there have been no large studies comparing different methods of ventilation. We aimed to compare the strategy of nonselective paralysis with that of synchonised (fast rate) ventilation and selective paralysis in infants receiving mechanical ventilation for respiratory distress syndrome with chronic lung disease as the primary outcome measure. severe lung damage and also in mortality.

\section{Patients and methods}

The study was performed between April 1990 and January 1993 at the Mersey Regional Neonatal Intensive Care Unit at Liverpool Maternity Hospital (during which period surfactant treatment was in routine use). The study was approved by the local ethics research committee. All babies weighing under $2000 \mathrm{~g}$ 
at birth who received mechanical ventilation within 24 hours of birth and who had respiratory distress syndrome were eligible for inclusion in the study. Respiratory distress syndrome was defined clinically: (1) in an infant not ventilated from birth when within the first four hours there was sternal retraction, intercostal and subcostal recession, grunting, tachypnoea, hypercapnia, an oxygen requirement above that of room air, and diffuse opacification on the chest radiograph with or without an air bronchogram and (2) in the infant who was intubated and had received mechanical ventilation from birth when diffuse opacification with or without an air bronchogram was present on the chest radiograph or if ventilatory requirements had increased over the first four hours. Infants with meconium aspiration syndrome, major malformations, or congenital heart disease were excluded from the trial.

Patent ductus arteriosus was defined as being present when the presence of a cardiac murmur with or without bounding peripheral pulses resulted in the infant being treated with fluid restriction and diuretics or indomethacin or surgical ligation. Intraventricular haemorrhage was defined by the appearance of the cerebral ultrasound scan as follows: grade 1, echodensity confined to the subependymal region; grade 2, echodensity extending into the cerebral ventricles but not the surrounding parenchyma with or without ventricular dilatation; and grade 3 (severe), echodensity extending into the cerebral parenchyma which persisted and resulted in cyst formation.

\section{TREATMENT ALLOCATION}

Once the decision had been made to institute mechanical ventilation, the infant's name, unit number, gestation, and birth weight were recorded on a standard proforma and they were randomised to one of two treatment groups. Randomisation was stratified into three groups (under $1000 \mathrm{~g}, 1000-1499 \mathrm{~g}$, and 1500-1999 g). The parents were informed of the need for mechanical ventilation and were provided with an information sheet concerning the trial.

\section{TREATMENT SCHEDULES}

(A) Ventilation with paralysis (non-selective group)

A starting ventilator rate of $40 \mathrm{bpm}$ was used with a peak inspiratory pressure of $24 \mathrm{~cm} \mathrm{H}_{2} \mathrm{O}$ and PEEP of $4 \mathrm{~cm} \mathrm{H}_{2} \mathrm{O}$. An inspiratory to expiratory time ratio of 1:1 was used initially and the initial fractional inspired oxygen $\left(\mathrm{FIO}_{2}\right)$ used was that which provided adequate oxygenation.

If the infant's mean blood pressure was above the 10th centile for gestational age, pancuronium in a dose of $80 \mu \mathrm{g} / \mathrm{kg}$ was administered as required to ensure paralysis from the beginning of mechanical ventilation. If mean blood pressure was below the 10th centile for gestational age, pancuronium was not given and ventilator settings were adjusted at the discretion of the attending clinician. If mean blood pressure rose to above the 10th centile for gestational age over the next 24 hours pancuronium was given to ensure paralysis. During subsequent management inspiratory and expiratory pressures, ventilatory rate and $\mathrm{FiO}_{2}$ were altered at the discretion of the attending clinician. Pancuronium was administered until the infant had been weaned to $30 \mathrm{bpm}$ and to an inspiratory pressure of $20 \mathrm{~cm} \mathrm{H} \mathrm{H}_{2} \mathrm{O}$ or earlier if the physician in charge considered that excessive fluid retention was occurring.

\section{(B) Synchronised (fast rate) ventilation (selective group)}

Once intubated the intrinsic respiratory rate of the infant was counted over 30 seconds while the infant was receiving continuous positive airways pressure. Following this the ventilatory rate in bpm was set at the infant's rate (this was set at 60 if the infant was apnoeic). Initial inspiratory to expiratory ratio was $1: 1$, peak inspiratory pressure was $24 \mathrm{~cm} \mathrm{H}_{2} \mathrm{O}$, and PEEP was $4 \mathrm{~cm} \mathrm{H}_{2} \mathrm{O}$. Initial $\mathrm{FIO}_{2}$ was that which provided adequate oxygenation. Inspiratory and expiratory pressures together with $\mathrm{FIO}_{2}$ were altered at the discretion of the attending clinician. However, the ventilator rate was maintained to at least that of the infant's respiratory rate.

If the infant constantly expired during the inspiratory part of the ventilator cycle and there was no improvement in oxygenation pancuronium was administered. This was stopped when the infant was weaned to $30 \mathrm{bpm}$ and to an inspiratory pressure of $20 \mathrm{~cm} \mathrm{H}_{2} \mathrm{O}$ or earlier if the physician in charge considered that excessive fluid retention was occurring. If the infant became unduly restless morphine was given intravenously every 12 hours at the discretion of the attending physician.

\section{WEANING AND BLOOD GASES}

Infants in both groups were weaned from mechanical ventilation, first by decreasing peak inspiratory pressure down to $12 \mathrm{~cm} \mathrm{H}_{2} \mathrm{O}$ if tolerated and then by decreasing the ventilatory rate, keeping the inspiratory time constantly less than 0.5 seconds. Ventilator parameters were set to maintain arterial oxygen tension between 6.67 and $10.00 \mathrm{kPa}$ and arterial carbon dioxide tension $\left(\mathrm{PaCO}_{2}\right)$ between 4.67 and $6.00 \mathrm{kPa}$.

\section{DATA RECORDING}

The maximum peak inspiratory pressure, highest $\mathrm{FIO}_{2}$, and lowest $\mathrm{PaCO}_{2}$ were recorded daily. The length of time of ventilation, incidence of death, patent ductus arteriosus, and pneumothorax were recorded. Cerebral ultrasound scanning was performed routinely in all infants and grade of intraventricular haemorrhage, together with presence of periventricular leukomalacia, were recorded. Chronic lung disease was defined as being present if the chest radiograph at 28 days of age showed diffuse opacification or had areas of hyperlucency 
Table 1 Demographic details and secondary outcome measures in selective and nonselective treatment groups

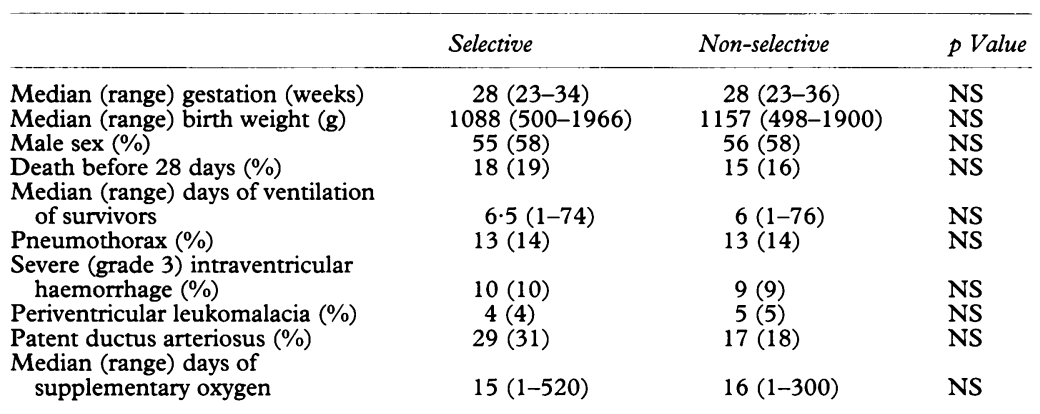

Table 2 Median (range) highest peak inspiratory pressure used and median lowest $\mathrm{PaCO}_{2}$ in first five days for each treatment group

\begin{tabular}{|c|c|c|c|}
\hline & Selective & Non-selective & p Value \\
\hline \multicolumn{4}{|c|}{ Peak inspiratory pressure $\left(\mathrm{cm} \mathrm{H}_{2} \mathrm{O}\right)$} \\
\hline Day 1 & $23(14-40)$ & $24(18-40)$ & $<0.05$ \\
\hline Day 2 & $19(3-36)$ & $22(3-40)$ & $<0.05$ \\
\hline Day 3 & $19(3-36)$ & $20(14-34)$ & NS \\
\hline Day 4 & $19(12-36)$ & $18(4-32)$ & NS \\
\hline Day 5 & $18(2-38)$ & $18(12-32)$ & NS \\
\hline \multicolumn{4}{|c|}{$\mathrm{PaCO}_{2}(\mathrm{kPa})$} \\
\hline Day 1 & $3 \cdot 87(1.47-6 \cdot 13)$ & $3 \cdot 87(2 \cdot 00-6 \cdot 27)$ & NS \\
\hline Day 2 & $4.67(2.53-6 \cdot 00)$ & $4 \cdot 27(2 \cdot 27-7 \cdot 07)$ & $<0.001$ \\
\hline Day 3 & $4.93(2 \cdot 13-6.93)$ & $4 \cdot 27(2 \cdot 13-6 \cdot 00)$ & $<0.001$ \\
\hline Day 4 & $4.93(2.007 .33)$ & $4 \cdot 67(2 \cdot 80-6 \cdot 40)$ & NS \\
\hline Day 5 & $4.93(2.53-7 \cdot 20)$ & $4 \cdot 80(2 \cdot 67-6 \cdot 53)$ & NS \\
\hline
\end{tabular}

interspersed with fine strands of opacification ${ }^{8}$ and the infant required supplementary oxygen to maintain oxygen saturations at $93 \%$ or above.

\section{STATISTICAL CONSIDERATIONS}

The incidence of chronic lung disease in 1988 and 1989 in the Mersey regional neonatal unit in infants weighing under $2000 \mathrm{~g}$ who received mechanical ventilation was approximately $35 \% .{ }^{9}$ It was therefore calculated that in order to detect a $50 \%$ difference in the incidence of chronic lung disease $(\alpha=0.05, \beta=0.2) 96$ infants were required for each treatment group. Statistical analysis was performed using the $\chi^{2}$ test and the Mann-Whitney U test.

\section{Results}

One hundred and ninety three infants were enrolled in the study, 96 were allocated to the non-selective group and 97 to the selective group. The median time of entry into the study was 3 hours (range 1-22 hours) for the nonselective group and 2 hours (range 1-17 hours) for the selective group.

Twenty five $(26 \%)$ of the selective group received pancuronium at some stage during mechanical ventilation while all of the nonselective group received pancuronium. Eighty five $(89 \%)$ infants in the non-selective group received artificial surfactant (Exosurf, Wellcome) by the endotracheal route compared with $93(96 \%)$ in the selective group. The median and range for gestational age and birth weight and also sex distribution for infants in each treatment group are shown in table 1. There was no significant difference between the groups with respect to the incidence of death before 28 days, the number of days of mechanical ventilation required in the survivors, pneumothorax, severe (grade 3) intraventricular haemorrhage, periventricular leukomalacia, patent ductus arteriosus, and the length of requirement for supplementary oxygen (table 1).

Forty seven per cent (38/81) of survivors of the non-selective group developed chronic lung disease compared with $49 \%$ (39/79) of survivors of the selective group; this difference was not statistically significant. Oxygen dependency at 36 weeks' postmenstrual age was present in $31(39 \%)$ of survivors in the nonselective group compared with $24(32 \%)$ in the selective group; this difference was also not statistically significant.

The median highest peak inspiratory pressure used (including the time spent receiving continuous positive airway pressure before extubation) for each of the first five days and the median lowest $\mathrm{PaCO}_{2}$ in the infant's blood for each of the first five days for each treatment group is shown in table 2 . Significantly higher peak inspiratory pressures were used for the first two days in the non-selective group and significantly lower $\mathrm{PaCO}_{2}$ was attained on days 2 and 3 in the non-selective group.

\section{Discussion}

We have compared the outcomes of two different methods of mechanical ventilation for respiratory distress syndrome - that is the strategy of paralysing only infants who fail to synchronise with the ventilator when a fast rate is being used with that of routinely paralysing all infants. As the study compared two different methods of 'synchrony' rather than the effect of using two different ventilator rates, it was possible that those randomised to the nonselective group could receive a fast ventilator rate of up to $90 \mathrm{bpm}$ if this was felt to be appropriate for the maintenance of optimal blood gases. As the aim of this study was to compare two strategies of neonatal ventilation rather than the effect of paralysis per se we have not compared the outcome of the non-paralysed infants with that of the non-selective group combined with the subgroup of infants within the selective group who were paralysed.

The study was confined to infants weighing under $2000 \mathrm{~g}$ as this constitutes a moderately high risk group for the development of chronic lung disease. Sample size was estimated on the basis of the incidence of chronic lung disease in infants admitted to the unit weighing under $2000 \mathrm{~g}$ and who had been ventilated during the two years before the study. ${ }^{9}$

This was a clinical study from which we aimed to optimise our guidelines for neonatal ventilation. We therefore used a clinical definition of respiratory distress syndrome that can be easily applied and is likely to be accepted in most neonatal intensive care units.

There has been concern that pancuronium may precipitate hypotension in the newborn. ${ }^{10}$ As a precaution infants with a mean blood pressure lower than the 10th centile for their gestation were not eligible to receive pancuronium unless their mean blood pressure rose above the 10th centile within the first 24 
hours. At the time of entry into the study, however, no infant in the non-selective group had a mean blood pressure so low as to preclude administration of pancuronium.

In both treatment groups the inspiratory time was maintained between $0 \cdot 3-0.5$ seconds during weaning from the ventilator. This has previously been shown to provide an adequate tidal volume and yet to minimise the possibility of the infant expiring against the inspiratory phase of the ventilator cycle. ${ }^{11}$ With the advent of surfactant treatment we have found that it is often possible during weaning to reduce the peak inspiratory pressure to $12 \mathrm{~cm} \mathrm{H}_{2} \mathrm{O}$ before reducing the ventilator rate and this was actively attempted in all infants.

Twenty five per cent of infants randomised to the selective group received pancuronium. This is lower than the reported need for paralysis when it has been used by others selectively for infants with respiratory distress syndrome. ${ }^{23}$ However, studies reporting a high incidence of use of paralysing agents are not strictly comparable with our own. Infants in these earlier studies were being mechanically ventilated using slower ventilator rates (around $40 \mathrm{bpm}$ ) than in the present study making them more likely to expire during the inspiratory phase of the ventilator cycle due to the longer inspiratory time used and therefore more likely to require pancuronium.

Both groups were well matched for birth weight, gestation, sex, and the use of surfactant. A small number of infants in each group did not receive surfactant. These were infants who had improved so rapidly that it was felt that it was not clinically indicated.

The incidence of chronic lung disease (our primary outcome measure) was no different in either group. This contrasts with the results of a previous study, which found a reduction in the incidence of chronic lung disease in ventilated infants who were paralysed. However, this study is not comparable with ours as it looked at the effects of using paralysis in infants ventilated at a slower rate $(40 \mathrm{bpm})$ and with a longer inspiratory time. ${ }^{4}$

The incidence of oxygen dependency at 36 weeks' postmenstrual age (more likely to occur in very low birthweight infants) was not statistically significantly different between the groups, although there was a trend towards the selective group showing a lower incidence. This implies that a policy of selective paralysis when ventilating very low birthweight infants may improve their respiratory outcome. This can be explained by postulating that if the very low birthweight infant is particularly susceptible to barotrauma then by avoiding the higher ventilatory pressures needed to treat a baby who is paralysed the risk of lung damage is reduced.

There was no difference in mortality, incidence of pneumothorax, or severe intraventricular haemorrhage between the two groups. The incidence of pneumothorax is similar to that previously observed for this unit, ${ }^{3}$ although lower than that reported for a group of non-paralysed infants in another study which had suggested that pancuronium prevents pneumothoraces. ${ }^{2}$ Our study again, however, is not strictly comparable with these other two owing to the slower ventilation rates used in the non-paralysed group in the latter.

There is no agreement as to whether neuromuscular paralysis reduces the incidence of intraventricular haemorrhage. ${ }^{12}$ Our study shows that administrating pancuronium did not reduce the incidence of intraventricular haemorrhage when those not receiving routine paralysis are ventilated at a faster ventilatory rate.

From the results of this study it appears that the use of synchronised (fast rate) ventilation with a selective paralysis policy is not associated with an increase in the incidence of long and short term respiratory or cerebral complications.

Treatment with neuromuscular paralysis has potential side effects. Pancuronium causes loss of muscle tone and ventilatory effort which may precipitate hypoxia due to inadequate chest wall movement or if the endotracheal tube becomes dislodged. Gas exchange over a more prolonged period may also be compromised. ${ }^{13}$ Hypotension with pancuronium has been reported, although it does not appear to be common. ${ }^{10} 14$ Oedema may produce difficulties in assessing fluid balance and may impair lung compliance. ${ }^{15}$ Joint contractures may also occur with long term paralysis.

Although in our study no significant adverse effects occurred as a result of using pancuronium, it seems that because of the potential side effects described above routine neuromuscular paralysis should be avoided if it confers no advantage. We therefore conclude that the strategy of synchronised (fast rate) ventilation with selective paralysis should be routinely used in preference to that of non-selective paralysis when ventilating infants with respiratory distress syndrome.

1 Ramsden CA, Reynolds EOR. Ventilator settings for newborn infants. Arch Dis Child 1987; 62: 529-38.

2 Greenough A, Morley CJ, Wood S, Davis JA. Pancuronium prevents pneumothoraces in ventilated premature babies who actively expire against positive pressure inflation. wancet 1984; i: $1-3$.

3 Cooke RWI, Rennie JM. Pancuronium and pneumothorax. Lancet 1984; i: 286-7.

4 Pollitzer MJ, Shaw DG, Reynolds EOR, Thomas RM. Pancuronium during mechanical ventilation speeds recovery of lungs of infants with hyaline membrane disease. Lancet 1981; i: 346-8.

5 South M, Morley CJ. Synchronous mechanical ventilation of the neonate. Arch Dis Child 1986; 61: 1190-5.

6 Field D, Milner AD, Hopkin IE. Manipulation of ventilator settings to prevent active expiration against positive settings to prevent active expiration against positive
pressure inflation. Arch Dis Child 1985; 60: 1036-40.

7 Greenough A, Greenall F. Observation of spontaneous respiratory interaction with artificial ventilation. Arch Dis respiratory interaction with

8 Hyde I, English RE, Williams JD. The changing pattern of chronic lung disease of prematurity. Arch Dis Child 1989; 64: 448-51.

9 Shaw NJ, Gill AB, Weindling AM, Cooke RWI. The changing incidence of chronic lung disease. Health Trends 1993 (in press).

10 McIntosh N. Hypotension associated with pancuronium use in the newborn. Lancet 1985; ii: 279.

11 Greenough A, Milner AD. Respiratory support using patient triggered ventilation in the neonatal period. Arch Dis Child 1992; 67: 69-71.

12 Levene MI, Quinn MW. Use of sedatives and muscle relaxants in newborn babies receiving mechanical ventilation. Arch Dis Child 1992; 67: 870-3.

13 Finer NN, Tanney PM. Controlled evaluation of muscle relaxation in the ventilated neonate. Pediatrics 1981; 67: 641-6.

14 Runkle B, Bancalari E. Acute cardiopulmonary effects of pancuronium bromide in mechanically ventilated newpancuronium bromide in mechanically
born infants. $\mathcal{F}$ Pediatr $1984 ; 104: 614-7$.

15 Bhutani VK, Abassi S, Sivilri EM. Continuous skeletal muscle paralysis: effect on neonatal pulmonary mechmuscle paralysis: effect on neonatal
anics. Pediatrics $1988 ; 88$ : 419-22. 